\title{
Experimental assessment of the influence of multiple cyclic loading on the dynamic modulus of elasticity of concrete
}

\author{
Petr Misák ${ }^{1,{ }^{*}}$, Dalibor Kocáb ${ }^{1}$, Petr Daněk ${ }^{1}$, Barbara Kucharczyková ${ }^{1}$ and Libor Topoláŕ ${ }^{1}$ \\ ${ }^{1}$ Brno University of Technology, Faculty of Civil Engineering, Veveři 95, 60200 Brno, \\ Czech Republic
}

\begin{abstract}
The goal of the experiment was to determine the influence that cyclic loading has on concrete dynamic modulus of elasticity and compressive strength. Each test specimen was subjected to cyclic loading with the loading force equivalent to one third of the expected compressive strength value similarly to the static modulus of elasticity test with the difference that the total number of loading cycles was 3000 . The dynamic modulus of elasticity was determined on every specimen before and after loading by means of the ultrasonic pulse velocity test and resonance method. The result of the experiment is the degree to which the dynamic modulus of elasticity decreased after multiple cyclic loading. A decrease was observed in all specimens.
\end{abstract}

\section{Introduction}

The elastic properties of hardened structural concrete have been seeing increased attention lately. The elastic modulus is undoubtedly one of the most important elastic properties of hardened concrete $[1,2]$. This property affects primarily deformation under load, the magnitude of deformation and shrinkage. Generally speaking, the higher the value of the modulus of elasticity, the less a structure deforms. During its service in a structure, concrete enters alternating states of loading and unloading, or states of greater and lesser loading. If situation in which a structure is at one point loaded and at another this load is reduced or removed can be called a loading cycle, then a structure can be considered to be cyclically loaded during its use. These cycles are irregular and can vary depending on the structure's purpose and manner of use.

This paper discusses a part of an experiment, which focused on the cyclic compressive loading of hardened concrete. Test specimens were loaded by 3000 loading cycles to elicit elastic deformation. The goal of the experiment was to determine the influence of such multiple cyclic loading on the dynamic compressive and tensile modulus of elasticity, the dynamic shear modulus of elasticity, the dynamic value of Poisson's ratio and compressive strength. The basic purpose of the experiment was the determination of how the observed properties develop depending on the number of loading cycles. This experiment is only a minor part (a pilot experiment) of a larger effort, the goal of which is to observe the change

Corresponding author: petr.misak@vutbr.cz 
in the static modulus of elasticity during cyclic loading alongside with the development of acoustic emission characteristics.

\section{Experiment}

The tests were performed with ordinary concrete of the C 35/45 strength class. Table 1 shows its composition and basic properties.

Table 1. Composition and basic properties of fresh and hardened concrete.

\begin{tabular}{|l|c|}
\hline CEM I 42,5 R [kg] & 338 \\
\hline Sand Bratčice 0-4 mm [kg] & 905 \\
\hline Aggregate Olbramovice 4-8 mm [kg] & 183 \\
\hline Aggregate Olbramovice $8-16 \mathrm{~mm}[\mathrm{~kg}]$ & 667 \\
\hline Water [kg] & 176 \\
\hline Plasticiser Sika ViscoCrete $4035[\mathrm{~kg}]$ & 1.77 \\
\hline w/c [-] & 0.48 \\
\hline Flow table test (fresh concrete) [mm] & 340 \\
\hline Slump test (fresh concrete) [mm] & 70 \\
\hline Air content (fresh concrete) [\%] & 4.5 \\
\hline Density (fresh concrete) $\left[\mathrm{kg} / \mathrm{m}^{3}\right]$ & 2270 \\
\hline $\begin{array}{l}\text { Compressive strength after } 28 \mathrm{days}(\text { cube, hardened } \\
\left.\text { concrete) [N/mm }{ }^{2}\right]\end{array}$ & 52.2 \\
\hline $\begin{array}{l}\text { Flexural strength after } 28 \mathrm{days}(\text { hardened concrete) } \\
\left.\text { [N/mm }{ }^{2}\right]\end{array}$ & 5.6 \\
\hline
\end{tabular}

The tests were performed with 12 cylindrical specimens with the diameter of $150 \mathrm{~mm}$ and height of $300 \mathrm{~mm}$. First, all the specimens were subjected to two tests. The ultrasonic pulse velocity test was used to determine the time taken by pulse to get through the concrete and the resonance method was applied to find out the actual frequency of longitudinal, flexural and torsional vibration. Fig. 2 shows the results of these tests. These parameters were then used in the calculation of the dynamic compressive/flexural and shear modulus of elasticity as well as Poisson's ratio. For more details about the dynamic methods, see e.g. [3-6]. Next, three specimens were tested for compressive strength. The remaining 9 specimens were cyclically loaded by up to one third of the determined value of compressive strength, similarly to the static elastic modulus test according to [7], except the number of loading cycles was 3000. After the cyclic loading test, all the specimens were tested for dynamic parameters and in the end also compressive strength. Because of the time needed for testing one specimen, which often took up to 3 days, it was necessary to make sure the testing time did not affect the results. This is why all tests were made at the age of 2 years, at which the properties of concrete are far more constant than at the age of e.g. 28 days.

The loading was performed in accordance with method B described in [7]. The testing procedure was configured in a way that allowed performing as many loading cycles as 
possible within several dozens of hours, while still performing a static loading test. The goal of the experiment was to observe the behaviour of concrete during loading in the elastic region of the stress-strain curve; for this reason, the upper loading stress was set to $\sigma_{a}=$ $f_{c} / 3$, where $f_{c}$ is compressive strength measured on reference specimens of the same shape and dimensions as the test specimens. According to [7], the basic loading force should be within $0.1 \cdot f_{c} \leq \sigma_{b} \leq 0.15 \cdot f_{c}$. This experiment used a lower loading stress of the highest possible value, i.e. $\sigma_{b}=0.15 \cdot f_{c}$. The reason for this was to save time when transferring between the loading stresses. For the same reason, the highest allowed loading rate was chosen to be $0.80 \mathrm{MPa} / \mathrm{s}$ with a holding time of $3 \mathrm{~s}$. The cyclic loading was performed using a mechanical testing press LaborTech with a loading force range of $0-1000 \mathrm{kN}$; the loading rate was set by a compressive force increment.
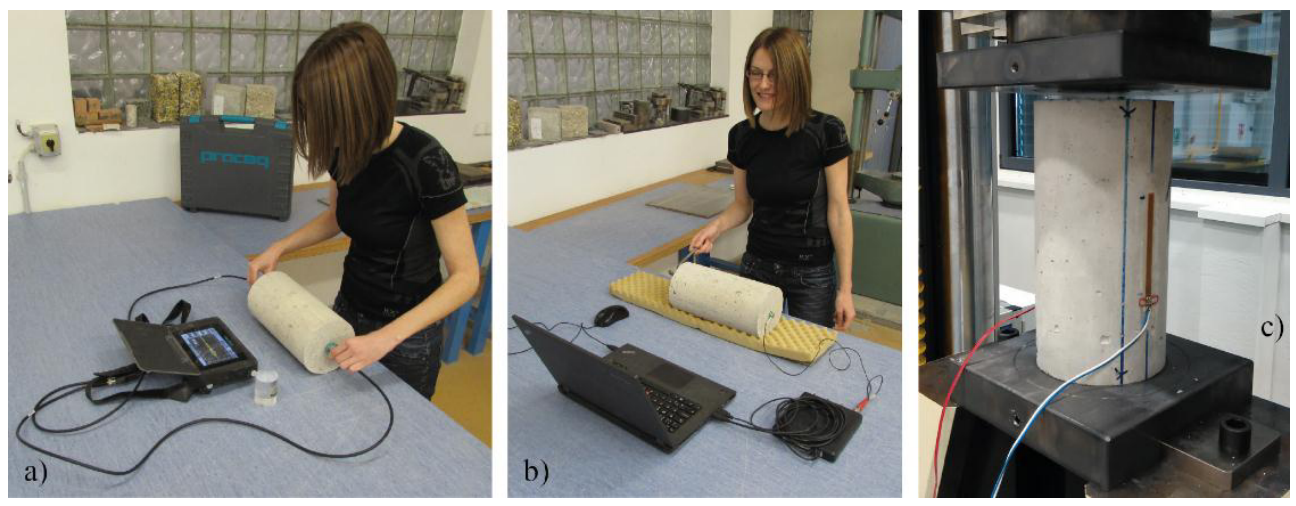

Fig. 1. a) Ultrasonic pulse velocity test. b) Determination of the natural frequency by the resonance method; c) Testing specimen.

\section{Results and discussion}

The result of the experiment described here is an evaluation of the drop in the dynamic modulus of elasticity. The following properties were determined:

- $E_{c u}-$ dynamic flexural and compressive modulus of elasticity determined by the ultrasonic pulse velocity test;

- $E_{c r L}-$ dynamic flexural and compressive modulus of elasticity determined from the natural frequency of longitudinal vibration - resonance method;

- $E_{c r f}$ - dynamic flexural and compressive modulus of elasticity determined from the natural frequency of flexural vibration - resonance method;

- $G_{c r}$-dynamic shear modulus of elasticity determined by the resonance method;

- $v_{c r}$-dynamic Poisson's ratio determined by the resonance method;

- $f_{c}$ - compressive strength.

All the non-destructively determinable properties (i.e. all except compressive strength) were determined before and after the cyclic loading using the same method and the same specimens. Only compressive strength was measured on three unloaded specimens and nine loaded ones. The results for all the properties are shown as standard boxplots in Fig. 2. 


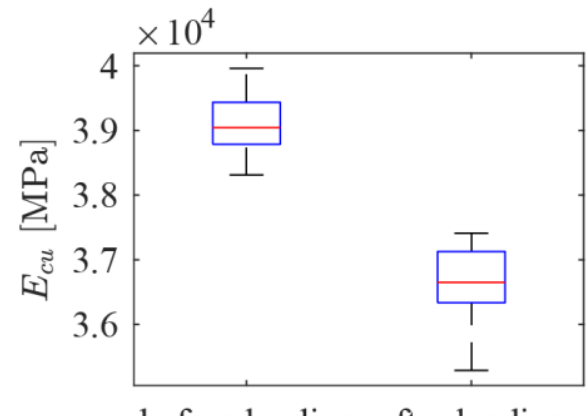

before loading after loading
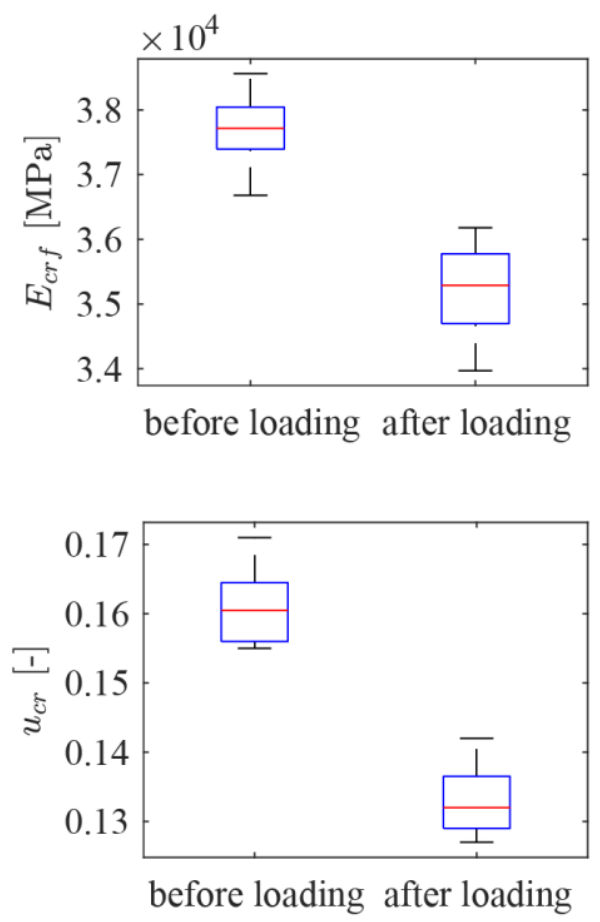
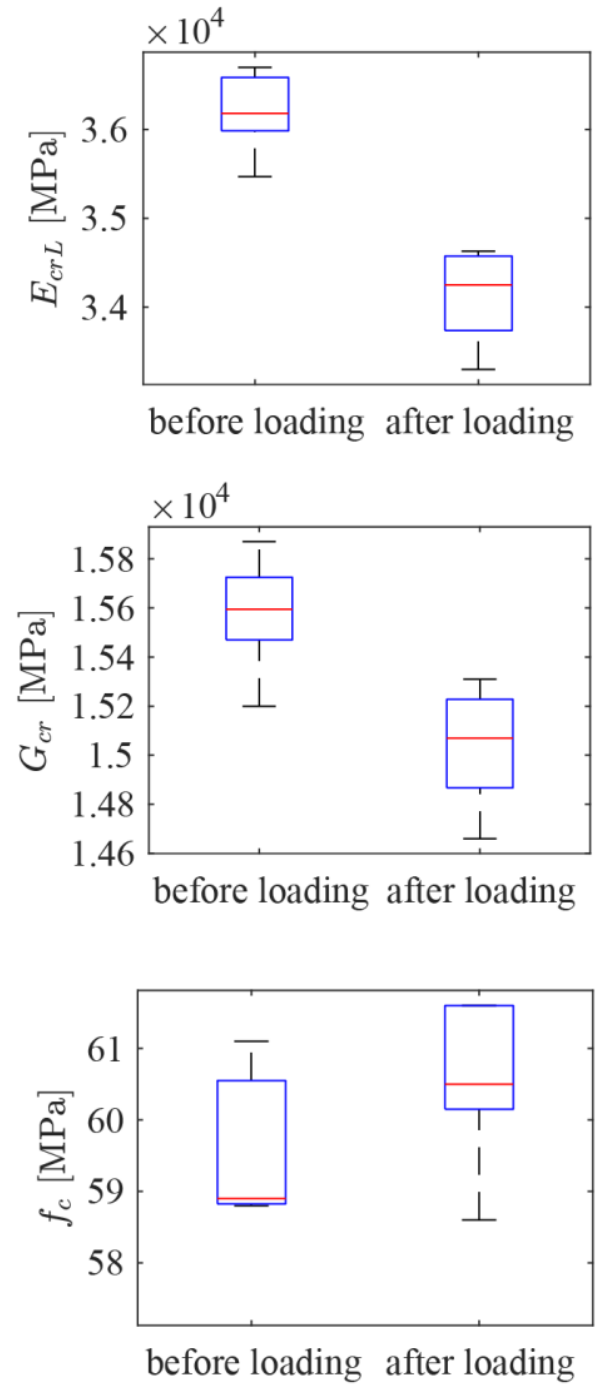

Fig. 2. Boxplots of the results; red line - median; blue box $-25 \%$ and $75 \%$ quantile; black lines minimum and maximum value.

The test results show that the multiple cyclic loading brought a decrease in all the observed properties with the exception of compressive strength, where no reduction was found. However, the compressive strength values can be influenced by the number of specimens used - only three specimens were tested for compressive strength before the cyclic loading. The drop in dynamic properties was measured by means of statistical tests. After the verification of data normality, the mean value equality hypothesis was refuted by the ANOVA test. Next, a one-tailed t-test was made, which returned the same result. The decrease in the dynamic properties caused by multiple loading can thus be considered statistically significant.

The authors of [8] attribute the drop in the elastic modulus to the formation of microcracks and creep. This explanation would correspond to the results presented herein, as microcracks and microfailures in the internal structure of concrete have a major influence on the dynamic modulus of elasticity without having any serious effect on compressive strength $[1,9]$. 


\section{Conclusion}

The experiment results invite the following conclusions:

- All the observed properties with the exception of compressive strength registered a decrease after multiple cyclic loading. No decrease in compressive strength after multiple loading cycles has been recorded.

- The decrease in the values of the observed properties corresponds with previously published conclusions [8], which, however, largely concern changes in the values of the static modulus.

- An evaluation of the dependence of the static modulus of elasticity on number of cycles, which was determined during every cycle of multiple cyclic loading. These findings are going to be published in near future.

This paper has been written as a part of project No. 17-14302S „Experimental analysis of the early-age volume changes in cement-based composites ", supported by the GAČR - Czech Science Foundation and project FAST-S-17-4693 supported by Brno University of Technology.

\section{References}

1. A. Neville, Properties of Concrete (Prentice Hall, New Jersey, 2012)

2. H. S. Abdelgader, A. S. Elbaden, A. Diouri, N. Khachani, M. Alami Talbi. MATEC Web of Conferences, 11 (2014)

3. ČSN 731371 Nedestruktivní zkoušení betonu - Ultrazvuková impulzová metoda zkoušení betonu (2011)

4. ČSN 731372 Nedestruktivní zkoušení betonu - Rezonanční metoda zkoušeni betonu (2012)

5. V. M. Malhotra, N. J. Carino, Handbook on non-destructive testing of concrete (CRC Press LLC, West Conshohocken, 2004)

6. D. Kocáb, M. Králíková, P. Cikrle, P. Misák, B. Kucharczyková, Mat. and Tech. (to be published)

7. ČSN EN 12390-13 Zkoušení ztvrdlého betonu - Část 13: Stanovení sečnového modulu pružnosti v tlaku (2014)

8. A. Neville, J. J. Brooks, Concrete technology (Harlow, Prentice Hall, 2010)

9. ASTM C 666/C, Standard Test Method for Resistance of Concrete to Rapid Freezing and Thawing (2003) 